\title{
Potential of bacteriophage $\Phi A B 2$ as an environmental biocontrol agent for the control of multidrug-resistant Acinetobacter baumannii
}

\author{
Li-Kuang Chen ${ }^{1,2}$, Yu-Lin Liư ${ }^{3}$, Anren Hü ${ }^{4}$, Kai-Chih Chang ${ }^{4}$, Nien-Tsung Lin ${ }^{5}$, Meng-Jiun Lai ${ }^{4}$ \\ and Chun-Chieh Tseng ${ }^{3 *}$
}

\begin{abstract}
Background: Multidrug-resistant Acinetobacter baumannii (MDRAB) is associated with nosocomial infections worldwide. To date, the use of a phage to prevent infections caused by MDRAB has not been demonstrated.

Results: The MDRAB-specific phage $\phi A B 2$ was stable at $4^{\circ} \mathrm{C}$ and $\mathrm{pH} 7$ in $0.5 \%$ chloroform solution, and showed a slight decrease in plaque-forming units (PFU)/ml of 0.3-0.9 log after 330 days of storage. The addition of $\phi A B 2$ at a concentration of at least $10^{5} \mathrm{PFU} / \mathrm{ml}$ to an A. baumannii M3237 suspension killed $>99.9 \%$ of A. baumannii M3237 after 5 min, regardless of $A$. baumannii M3237 concentration $\left(10^{4}, 10^{5}\right.$, or $10^{6}$ colony-forming units (CFU)/ml). The addition of $\phi A B 2$ at a concentration of $10^{8} \mathrm{PFU} /$ slide $\left(>10^{7} \mathrm{PFU} / \mathrm{cm}^{2}\right)$ to glass slides containing A. baumannii M3237 at $10^{4}, 10^{5}$, or $10^{6} \mathrm{CFU} / \mathrm{slide}$, significantly reduced bacterial numbers by $93 \%, 97 \%$, and $99 \%$, respectively. Thus, this concentration is recommended for decontamination of glass surfaces. Moreover, infusion of $\phi A B 2$ into $10 \%$ glycerol exhibited strong anti-MDRAB activity (99.9\% reduction), even after 90 days of storage. Treatment of a 10\% paraffin oil-based lotion with фAB2 significantly reduced (99\%) A. baumannii M3237 after 1 day of storage. However, фAB2 had no activity in the lotion after 1 month of storage.
\end{abstract}

Conclusions: Phages may be useful for reducing MDRAB contamination in liquid suspensions or on hard surfaces. Phages may also be inoculated into a solution to produce an antiseptic hand wash. However, the phage concentration and incubation time (the duration of phage contact with bacteria) should be carefully considered to reduce the risk of MDRAB contamination.

Keywords: Bacteriophage, Biocontrol, MDRAB

\section{Background}

Acinetobacter baumannii is a Gram-negative coccobacillus frequently associated with nosocomial infections worldwide $[1,2]$. It is an opportunistic pathogen with a wide spectrum of clinical manifestations, including pneumonia, meningitis, and blood stream, urinary tract, and wound infections $[3,4]$. A. baumannii has developed resistance to broad-spectrum antibiotics and has thus become problematic in intensive care units (ICUs) [5]. In Taiwan, the first multidrug-resistant A. baumannii (MDRAB) strain was identified in 1998 [6]. This strain

\footnotetext{
* Correspondence: tsengcc@mail.tcu.edu.tw

${ }^{3}$ Department and Graduate Institute of Public Health, Tzu Chi University, Hualien, Taiwan

Full list of author information is available at the end of the article
}

was among the top three pathogens causing nosocomial infections in ICUs in Taiwan from 2003-2009 [7], and the incidence of MDRAB infections worldwide has continued to increase [5,8-10].

Nosocomial MDRAB infections are usually transmitted between patients by contaminated health-care personnel [11]. Therefore, there is growing interest in controlling the spread of MDRAB caused by health-care workers, contaminated equipment, and ICU environments through disinfection methods. To date, several disinfection techniques have been evaluated for inactivating A. baumannii, including pasteurization [12], ultraviolet light [13], chemical sanitizers [14-16], ozone [17], and photocatalysis [18]. These sterilization techniques are highly effective in reducing $A$. baumannii 
contamination, but may be harmful to humans or surface materials in the ICU environment. Moreover, extensive use of chemicals can cause bacteria to develop resistance to chemical sanitizers [16,19]. For example, the growth and virulence of MDRAB are enhanced following exposure to ethanol and alcohol-based hand rubs [20]. Thus, there is an immediate need to develop alternative strategies for preventing the spread of MDRAB.

Bacteriophages (phages) are natural parasites of bacteria and are extremely host-specific. Therefore, the use of phages to reduce the concentration of specific bacterial foodborne pathogens has gained increasing attention [21-24]. For example, phages have been used to treat foods contaminated with strains of Campylobacter [22], Enterobacter [25], Escherichia coli O157 [26], Listeria [23], Salmonella [27], and Staphylococcus [28,29]. The levels of these bacterial pathogens have been successfully reduced by 1-5 logs, depending upon the method used. Moreover, the United States Food and Drug Administration has already approved the use of a Listeria-specific phage, Listex P100, for food preservation [30]. Although these studies suggest that bacteriophages might be highly effective in reducing MDRAB levels, this has not been studied in detail.

Although phages can significantly reduce the amount of pathogenic bacteria in liquid foods [22-24], the use of phages to reduce the levels of bacteria on hard surfaces has rarely been studied. Culture-positive swab samples of MDRAB have been recovered from frequently touched surfaces in ICUs [14,31]. These observations indicate the possible role of environmental surfaces in the spread of MDRAB [32]. Liquid suspensions containing a high concentration of phages allow the free diffusion of phages to ensure contact with their specific host [23]. However, for hard surfaces, an uneven and large surface area may limit the distribution of phage particles and decrease their ability to reach their bacterial targets [26]. This is especially true for low concentrations of bacteria that are unevenly distributed in the environment [33]. Therefore, the effects of phage concentration, host cell concentration and incubation time (the duration of phage contact with bacteria) on the degree of biocontrol on hard surfaces should be further investigated.

Despite intensive programs to encourage hand washing by health-care personnel, there is still a high rate of MDRAB transmission in ICUs. O'Flaherty [34] demonstrated the inclusion of phage $\mathrm{K}$ in an oil-based cream killed Staphylococcus aureus on agar and in broth cultures. Thus, a phage-containing hand cream could reduce pathogenic bacteria [34]. However, that study did not report on the stability of phages in the cream or on the exact degree of the bactericidal effect achieved. If a phage-containing cream were feasible for infection control, this approach would likely reduce the transmission of MDRAB from the hands of health-care personnel to patients in ICUs.

The first lytic phage shown to specifically infect MDRAB was characterized in 2010 [35] and belonged to the Podoviridae family, with a broad host range amongst MDRAB strains. This is the only known phage capable of infecting A. baumannii ATCC17978, whose genome has been fully sequenced [35]. In addition, $\phi A B 2$ can rapidly adsorb to its host and has a large burst size [35]. These advantages make $\phi A B 2$ a good model phage for controlling the prevalence of nosocomial infections caused by MDRAB. To our knowledge, most biocontrol studies have focused on using phages as food decontaminants $[21,23,26,36,37]$. The application of a phage as a disinfectant agent for the control of MDRAB has not been previously reported. Consequently, this study aimed to evaluate the ability of $\phi A B 2$ phage to reduce MDRAB in suspension and on experimentallycontaminated glass surfaces. In addition, the ability of $\mathrm{AB} 2$ in a paraffin oil-based lotion or glycerol to reduce the number of viable MDRAB was determined. The stability of $\phi \mathrm{AB} 2$ under different environments (temperature, $\mathrm{pH}$, chloroform, and glass surface) was also evaluated.

\section{Results}

Adsorption and one-step growth curve of $\varphi \mathrm{AB} 2$

фAB2 rapidly was adsorbed onto both $A$. baumannii M3237 and A. baumannii ATCC 17978 (Figure 1). Within 5 min, greater than $95 \%$ of the phage particles were adsorbed to $A$. baumannii M3237 and A. baumannii ATCC 17978 , and nearly $100 \%$ were adsorbed by $10 \mathrm{~min}$.

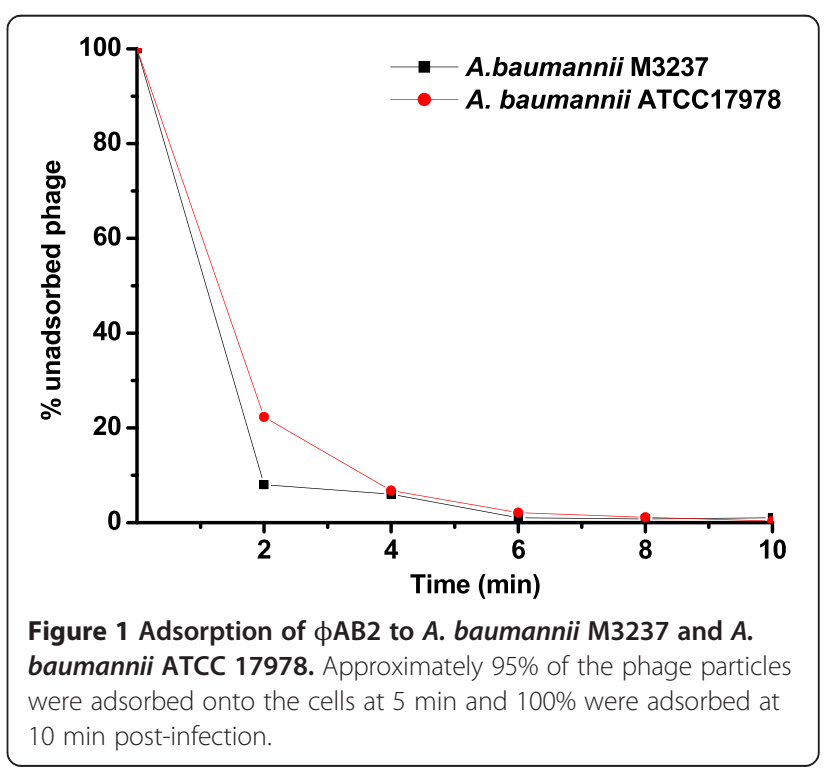




\section{Effect of temperature on $\phi A B 2$ stability}

Figure $2 \mathrm{~A}$ shows the stability of $\phi \mathrm{AB} 2$ stored in deionized water at $-20^{\circ} \mathrm{C}, 4^{\circ} \mathrm{C}$, and $25^{\circ} \mathrm{C}$, over 360 days. When the phages were stored in deionized water at $-20^{\circ} \mathrm{C}, 25^{\circ} \mathrm{C}$, and $4{ }^{\circ} \mathrm{C}$ for 360 days they retained $0.6 \%$, $1.0 \%$, and $66.0 \%$ of infectivity, respectively. Although \$AB2 had infectivity retention of more than $50 \%$ when stored in deionized water after 360 days at $4^{\circ} \mathrm{C}$, infectivity retention of more than $50 \%$ was only observed up to 220 days in samples stored at $-20^{\circ} \mathrm{C}$ or $25^{\circ} \mathrm{C}$. The effect of refreezing on phage survival demonstrated that $\phi A B 2$ was unstable when the sample was frozen repeatedly, as greater than $99.9 \%$ of phages lost infectivity after refreezing during a 360-day storage period at $-20^{\circ} \mathrm{C}$.

\section{Effect of $\mathrm{pH}$ on $\phi A B 2$ stability}

The optimal $\mathrm{pH}$ for $\phi \mathrm{AB} 2$ stability was determined (Figure 2B). фAB2 was relatively stable following 360-day incubation at $\mathrm{pH} 7$. Under these conditions, there was a 2-log decrease in $\phi A B 2$ phage titers from the initial titer of $10^{8} \mathrm{PFU} / \mathrm{ml}$. However, $\phi \mathrm{AB} 2$ titers decreased by over 5-logs after 180-day incubation at $\mathrm{pH} 4$ or $\mathrm{pH} 11$. In extremely acidic conditions, at $\mathrm{pH} 2$, no $\phi \mathrm{AB} 2$ plaques were identified after $10 \mathrm{~min}$ (data not shown). Thus, $\phi A B 2$ is unstable under extreme $\mathrm{pH}$ conditions.

\section{Effect of chloroform concentration on $\phi A B 2$ stability} $\phi A B 2$ titers were reduced following exposure to chloroform concentrations of $0.5 \%$ and $2 \%$ (Figure 2C). For phage purification, a chloroform concentration of 0.5 $2 \%(\mathrm{v} / \mathrm{v})$ is typically used, thus the infectivity of $\phi \mathrm{AB} 2$ following exposure to $0.5 \%$ and $2 \%$ chloroform was investigated. $\phi A B 2$ exposed to $0.5 \%$ chloroform retained stable infectivity of greater than $20 \%$ following a 360 -day storage period. However, infectivity retention of $\phi A B 2$ was only $5 \%$ following a 360 -day storage period in $2 \%$ chloroform (Figure 2C).

\section{$\phi A B 2$ stability on glass slides}

Desiccation reduced the stability of $\phi A B 2$ when spiked onto a glass surface over a 65-day period (Figure 2D). There was a $1-\log$ decrease in $\phi A B 2$ titers (initial phage concentration of $10^{8} \mathrm{PFU} /$ slide) after $12 \mathrm{~h}$ on the glass surface. Infectivity of $\phi A B 2$ on a glass slide was $0.1 \%$ after 7 days and $0.001 \%$ after 30 days. Thus, $\phi A B 2$ could survive on a dried glass surface for 2 months, although a large reduction in $\phi \mathrm{AB} 2$ titers was observed.

\section{Reduction of MDRAB by $\phi A B 2$ in a liquid suspension}

We next assessed the ability of $\phi A B 2$ to reduce the concentration of A. baumannii M3237 in sterile water over different incubation times (the duration of contact of the phages with the hosts). The addition of $\phi \mathrm{AB} 2$ to a liquid

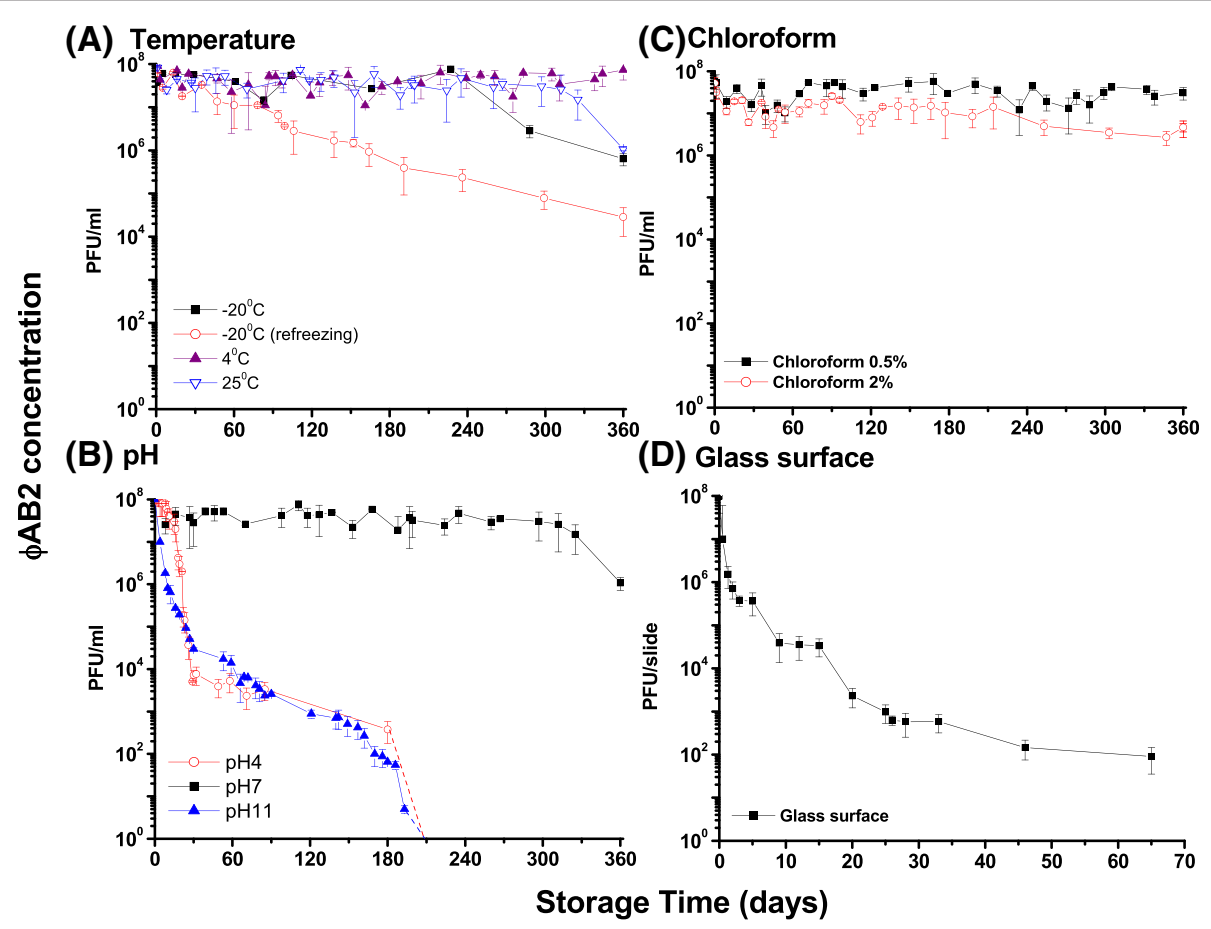

Figure 2 Stability of $\phi A B 2$ under (A) temperature, (B) pH, (C) chloroform, and (D) glass surface. The dotted line indicates no plaque survival at the respective storage time. These experiments were repeated three times and the data shown are the mean \pm SEM. 
suspension of A. baumannii M3237 had a strong bactericidal effect in all test groups except the 5 min incubation low dose group $\left(10^{3} \mathrm{PFU} / \mathrm{ml}\right)$ (Figure 3$)$. The $\phi \mathrm{AB} 2 \mathrm{bac}-$ tericidal effect showed a dose-response as the lowest concentration of $\phi \mathrm{AB} 2$ tested $\left(10^{3} \mathrm{PFU} / \mathrm{ml}\right)$ exhibited the weakest bactericidal capability, which was 6,600-fold lower than when higher phage concentrations $\left(10^{5}\right.$ and $10^{8}$ $\mathrm{PFU} / \mathrm{ml}$ ) were used (Figure 3A). The addition of $10^{5}$ or $10^{8} \mathrm{PFU} / \mathrm{ml}$ \$AB2 reduced the number of $A$. baumannii M3237 by at least 3-logs at all bacterial test concentrations after $5 \mathrm{~min}$. After $10 \mathrm{~min}$ incubation, the effect was even greater, with at least a 4-log reduction in MDRAB survival rates (Figure $3 \mathrm{~B}$ and $\mathrm{C}$ ). In addition, the mean reduction in bacteria was greater when a higher initial bacterial concentration was used. Thus, the same concentration of фAB2 had a stronger bactericidal effect when added to high bacterial concentrations $\left(10^{5}\right.$ and $\left.10^{6} \mathrm{CFU} / \mathrm{ml}\right)$ compared with low bacterial concentrations $\left(10^{4} \mathrm{CFU} / \mathrm{ml}\right)$. All control groups showed a $100 \%$ survival rate. In addition to the phage and bacterial host concentrations, the incubation time was also important for the bactericidal effect. Approximately 95\% of phage particles adsorbed to host cells within 5 min, and nearly $100 \%$ were adsorbed by 10 min (Figure 1). Therefore, we selected the 5 and $10 \mathrm{~min}$ time points to test the bactericidal effect of $\phi A B 2$ in suspension. At a low phage concentration $\left(10^{3} \mathrm{PFU} / \mathrm{ml}\right)$, an increase in the incubation time from 5 to $10 \mathrm{~min}$ resulted in a mean decrease of survival rate of MDRAB between 1.5 - and 1,700-fold. In contrast, at higher phage concentrations $\left(10^{5} \mathrm{PFU} / \mathrm{ml}\right.$ and $\left.10^{8} \mathrm{PFU} / \mathrm{ml}\right)$ there was a mean reduction of bacterial concentration of 1.4- to 7-fold when the incubation time was increased from 5 to $10 \mathrm{~min}$.

\section{Bactericidal effect of $\phi A B 2$ on a hard surface}

The addition of $\phi A B 2$ to a hard glass surface contaminated with $A$. baumannii M3237 had a bactericidal effect under some conditions (Figure 4). Phage concentrations of $10^{3}$ and $10^{5} \mathrm{PFU} /$ slide caused a significant reduction $(p<0.05,40 \%$ reduction) of $A$. baumannii M3237 cells $\left(10^{4}\right.$ and $10^{5} \mathrm{CFU} /$ slide) after $10 \mathrm{~min}$ (Figure $4 \mathrm{~A}$ and $\mathrm{B}$ ). When a phage concentration of $10^{8}$ PFU/slide was used, the number of $A$. baumannii M3237 was significantly reduced $(p<0.05$, $>90 \%$ reduction) after 5 or $10 \mathrm{~min}$ for all concentrations of bacteria tested (Figure 4C). However, the bactericidal effect of фAB2 at $10^{8} \mathrm{PFU} / \mathrm{slide}$ was significantly lower for $A$. baumannii M3237 at $10^{4}$ and $10^{5} \mathrm{CFU} /$ slide than at $10^{6}$ CFU/slide $(p<0.05)$. To date, there is no standard method for evaluating phage biocontrol efficiency on a hard surface. Incubation times of 5 and $10 \mathrm{~min}$ were chosen for surface tests on the basis of $\phi \mathrm{AB} 2$ adsorption data (Figure 1) and a previous study by Abuladze et al. [26]. Extending the incubation time from 5 to $10 \mathrm{~min}$ increased the mean bactericidal effect on A. baumannii M3237 1.3-fold under all test conditions.

\section{Use of $\phi A B 2$ as a hand sanitizer in a paraffin oil-based lotion}

The stability of $\phi \mathrm{AB} 2$ in a lotion and its ability to kill $A$. baumannii M3237 when spread on agar (at a volume of $0.1 \mathrm{ml}$ ), were evaluated to determine the potential of фAB2 as a hand lotion antiseptic. Prior to the addition of the phage lotion, lysogeny broth (LB) agar was precontaminated with approximately $5 \times 10^{1}, 5 \times 10^{2}$, or $5 \times$ $10^{3} \mathrm{CFU} / \mathrm{ml}$ (coefficient variation \% $\left.(\mathrm{CV} \%)=3.0 \%\right)$ of $A$. baumannii M3237 (Figure 5). The initial phage concentration in the lotion was $10^{8} \mathrm{PFU} / \mathrm{ml}$; however, this concentration decreased by approximately $98 \%$ after 10 days of storage $(p<0.05)$. Phage lotion stored for 1 day significantly reduced $(p<0.05)$ viable $A$. baumannii M3237 at initial concentrations of $10^{1}, 10^{2}$ and $10^{3} \mathrm{CFU} / \mathrm{ml}$ on agar, by $97.6 \%$, 99.8\%, and $99.9 \%$, respectively. Lotion

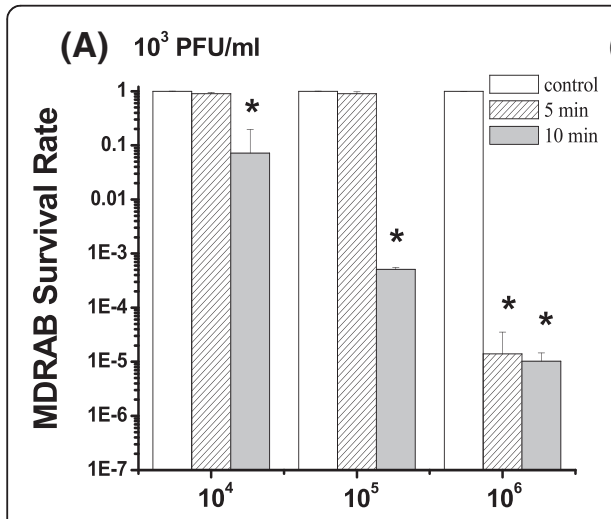

(B) $10^{5} \mathrm{PFU} / \mathrm{ml}$

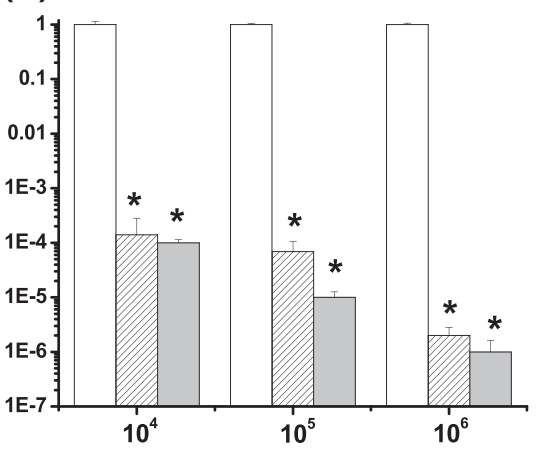

A.baumannii M3237 Concentration (CFU/ml)
(C) $10^{8} \mathrm{PFU} / \mathrm{ml}$

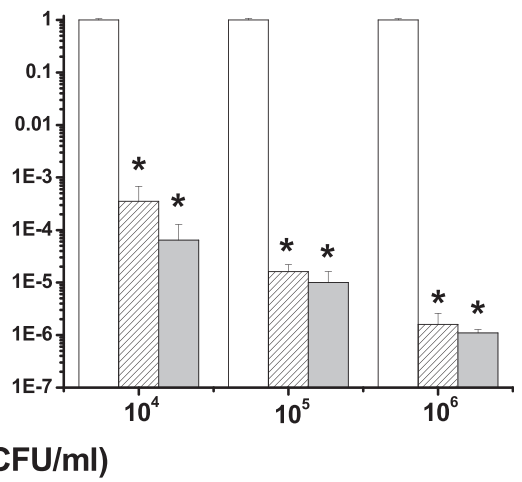

Figure 3 Bactericidal effect of different concentrations: (A) $10^{3}$ (B) $10^{5}$, and (C) $10^{8} \mathrm{PFU} / \mathrm{ml}$ of $\phi A B 2$ on different concentrations of $A$. baumannii M3237 in a liquid suspension, at incubation times of 5 and $10 \mathrm{~min}$. The survival rate was calculated as in the Methods section. These experiments were repeated three times, and the data shown are the mean \pm SEM. ${ }^{*} \mathrm{p}<0.05$ compared with the respective control group. 


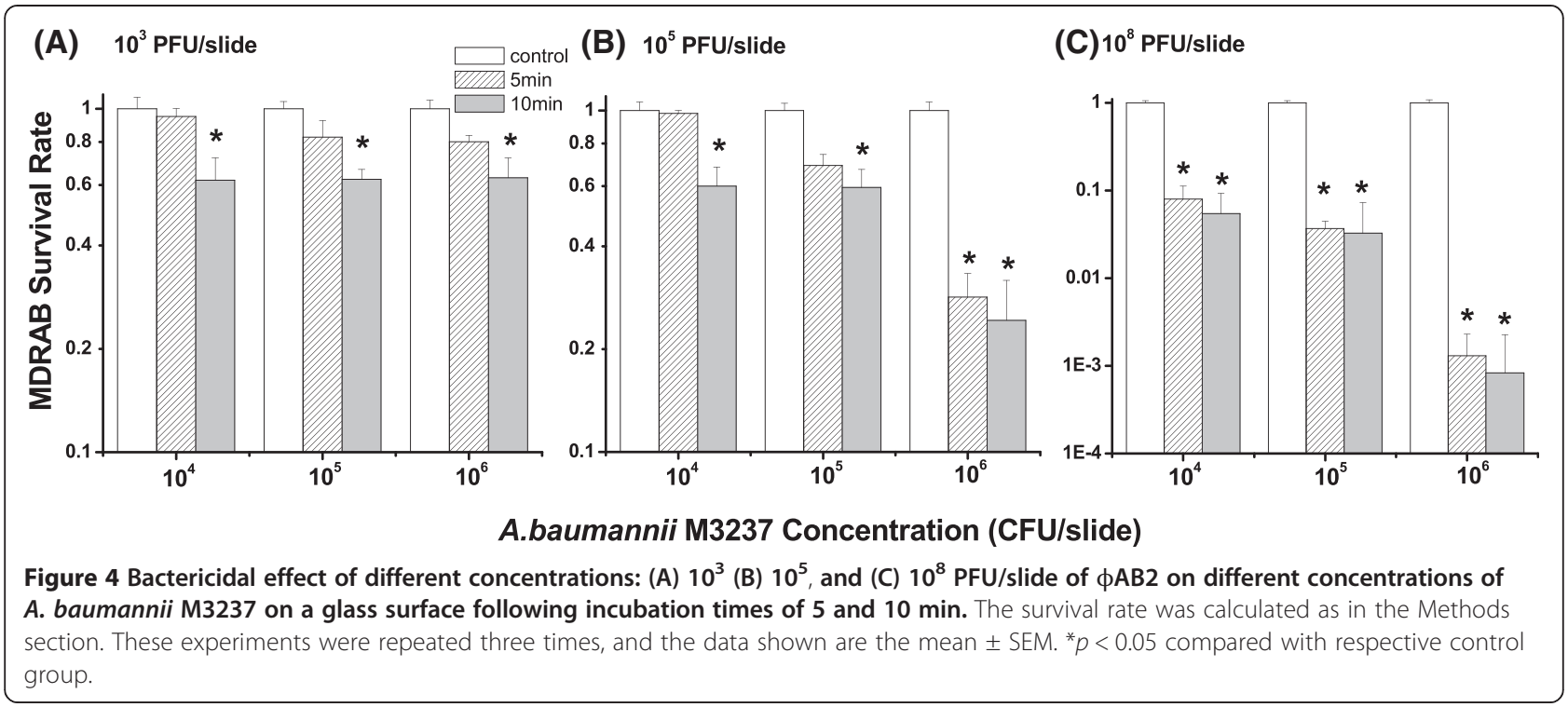

stored for 5 days also significantly reduced $(p<0.05)$ the concentration of viable A. baumannii M3237 by $92 \%$, $88 \%$, and $90 \%$, respectively. Lotion stored for longer than 5 days could not effectively reduce the A. baumannii M3237 concentration. Spreading a larger volume (0.5 $\mathrm{ml}$ ) of lotion on agar did not significantly alter the number of A. baumannii M3237 killed by the phage, as compared with a smaller volume $(0.1 \mathrm{ml})$.

\section{Use of $\phi A B 2$ as a hand sanitizer in glycerol}

Glycerol is used by the cosmetics industry to retain moisture in the skin. Therefore, the addition of $\phi A B 2$ to glycerol may be an effective way to formulate a hand sanitizer that can decrease MDRAB contamination and retain moisture within the skin. Because the amount of glycerol in cosmetic products varies (usually less than $20 \%)$, a concentration of $10 \%(\mathrm{v} / \mathrm{v})$ glycerol was evaluated in this study. Prior to the addition of the phage- containing glycerol, LB agar was pre-contaminated with approximately $5 \times 10^{1}, 5 \times 10^{2}$, or $5 \times 10^{3} \mathrm{CFU} / \mathrm{ml}(\mathrm{CV} \%=$ 12.3\%) of A. baumannii M3237 (Figure 6). The $\phi A B 2$ phage concentration $\left(10^{8} \mathrm{PFU} / \mathrm{ml}\right)$ did not significantly decrease (less than a 1-log decrease) when added to a glycerol solution and stored for 90 days. The application of phage-containing glycerol stored for 90 days to inoculated agar significantly reduced $(p<0.05)$ the mean concentration of viable A. baumannii M3237 by $99.9 \%$, regardless of the initial bacterial concentration. After 180 days of storage, $\phi \mathrm{AB} 2$ titers were decreased by approximately 2logs $(p<0.05)$. The application of phage-containing glycerol stored for 180 days reduced the mean concentration of viable A. baumannii M3237 by $62.4 \%, 86.2 \%$, and 98.6\% when the initial concentration of $A$. baumannii M3237 was $10^{1} \mathrm{CFU} / \mathrm{ml}, 10^{2} \mathrm{CFU} / \mathrm{ml}$, and $10^{3} \mathrm{CFU} / \mathrm{ml}$, respectively. Similar to the effect observed with the lotion, the bactericidal effect of spreading a larger volume $(0.5 \mathrm{ml})$

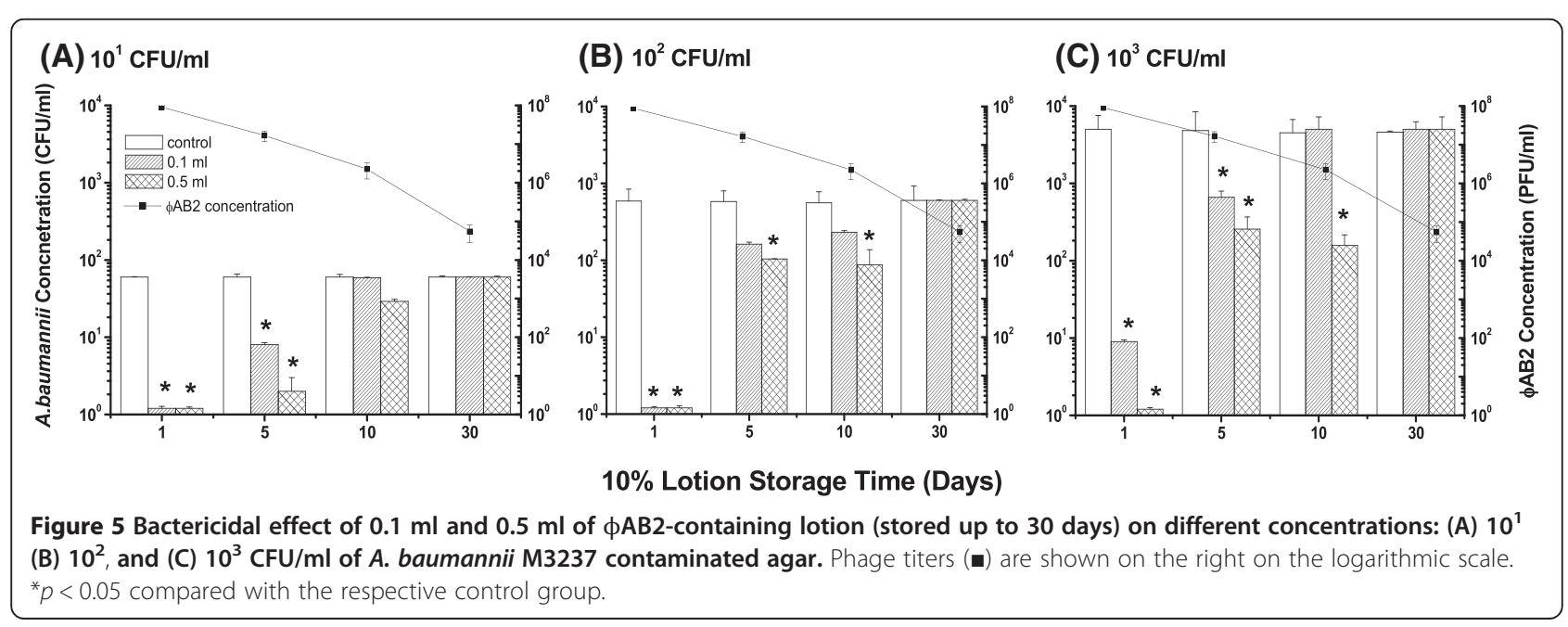




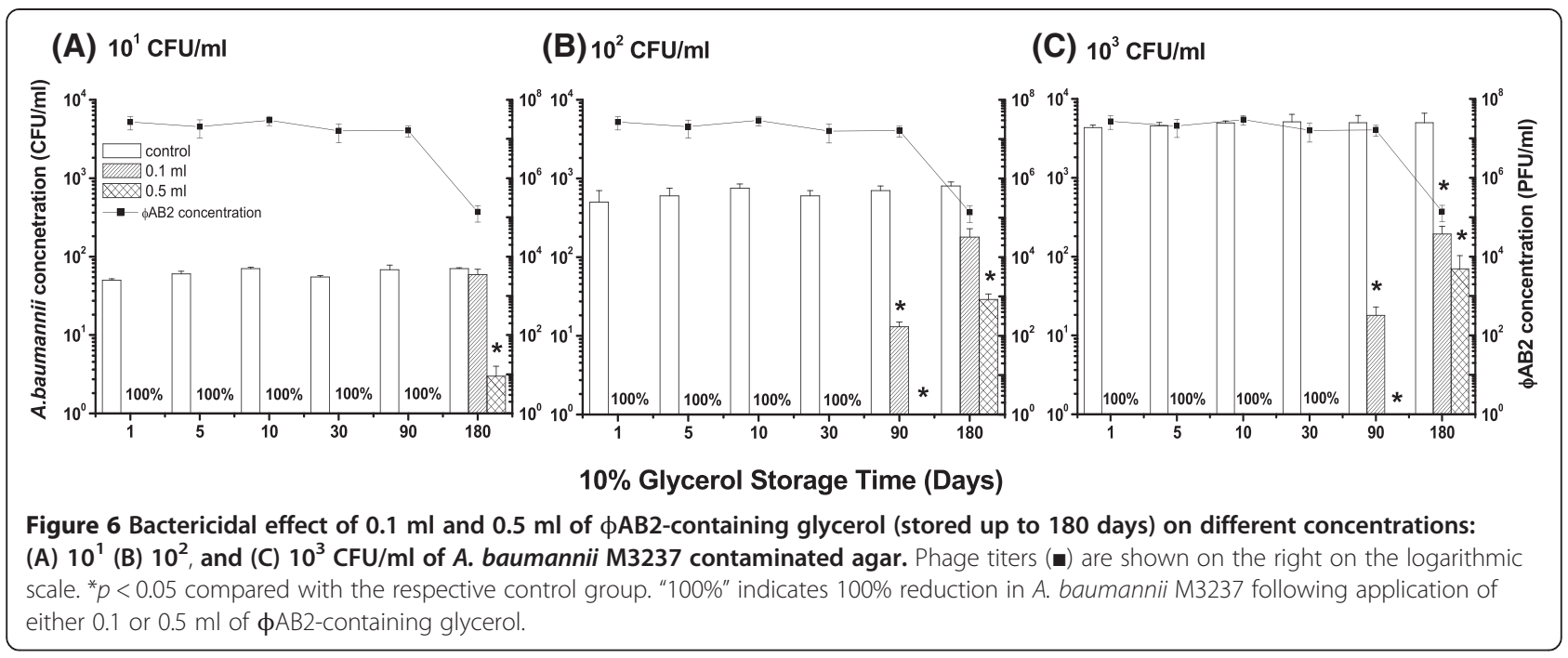

of the phage-containing glycerol on agar was not significantly different from that of a smaller volume $(0.1 \mathrm{ml})$.

\section{Discussion}

To date, most biocontrol studies have used phages for the decontamination of food and limited data are available concerning the stability of phages in an environmental matrix. Furthermore, the use of a phage to prevent infections caused by MDRAB has not been demonstrated. The $\phi A B 2$ phage was selected as a model phage for this study because its DNA and protein profiles were previously determined [35]. The current study demonstrated that phages such as the $\phi A B 2$ phage might be useful for reducing MDRAB contamination in liquid suspensions or on hard surfaces such as may be encountered in ICUs, and may be added to a solution to produce an antiseptic hand wash.

One issue with the human use of phages is their potential toxicity. Previously, we demonstrated $\phi A B 2$ had 91-99\% DNA sequence identity with the fully sequenced $\phi A B 1$ and that to date, no putative or confirmed toxin genes have been identified in $\phi A B 2$ [38]. In addition, no prophage-related genes were observed in $\phi A B 1$, although Vallenet et al. suggested that putative prophage sequences account for $5.1 \%$ and $6.7 \%$ of the genomes of both A. baumannii strains [39]. Thus, it is reasonable to assume that $\phi A B 2$ has no toxin genes or prophagerelated genes, and we predict there will no safety issues related to toxin production or chromosomal integration of $\phi \mathrm{AB} 2$.

There have been limited studies regarding environmental effects on phage stability. A previous study investigated another A. baumannii-specific phage, AB1, which is relatively heat resistant and can survive temperatures of $50-60^{\circ} \mathrm{C}$, and even a 15 -min incubation at $90^{\circ} \mathrm{C}$ [40]. The stability of $\phi \mathrm{AB} 2$ at extremely high temperatures was not evaluated in the present study because $\phi A B 2$ is proposed for use as an alternative sanitizer, so information regarding its stability for long storage periods at refrigerated or freezing temperatures was more relevant. Our study demonstrated that phage infectivity is strongly dependent on environmental conditions such as temperature, $\mathrm{pH}$, and the presence of other organic substances. Investigation of the optimal $\mathrm{pH}$ for maintaining $\phi \mathrm{AB} 2$ infectivity demonstrated that the least damaging $\mathrm{pH}$ tested was $\mathrm{pH} 7$, similar to the sewage from which $\phi A B 2$ was isolated ( $\mathrm{pH} 7.8)$. Yang et al. also demonstrated that the AB1 phage was most stable at $\mathrm{pH} 6$, and that less than $42.9 \%$ of $\mathrm{AB} 1$ phages lost their infectivity in a range between $\mathrm{pH}$ 5-9 [40]. Thus, our environmental stability results indicated that $\phi A B 2$ should be stored in a $\mathrm{pH} 7$ solution at $4^{\circ} \mathrm{C}$ for extended storage if $\phi A B 2$ is incorporated into a detergent.

Because MDRAB survives for long periods on environmental surfaces and may promote cross-transmission, we investigated the efficiency of $\phi A B 2$ in reducing $A$. baumannii M3237 contamination on surfaces. We observed the $\phi A B 2$ concentration required to reduce $A$. baumannii M3237 contamination was lower for liquid suspensions than hard surfaces. The mean survival rate ratio of A. baumannii M3237 between surface and liquid suspension ranged from 2-10,151 depending on the phage concentration. As $\phi A B 2$ does not diffuse as freely on a hard surface as in a suspension, a higher concentration of $\phi A B 2$ was required for surface decontamination of MDRAB compared with in solution.

The ability of phages to persist on a surface for extended periods is limited by many factors, such as desiccation [37], which may explain the loss of $\phi A B 2$ infectivity after 2 months storage on a glass surface. Because $\phi A B 2$ cannot survive for long periods on a hard surface, the phage detergent must be frequently re- 
applied to surfaces to provide persistent bactericidal or MDRAB activity.

Previous biocontrol studies suggested that high phage numbers should be used without relying on phage amplification [22,23]. Although $\phi A B 2$ has a larger burst size than other phages [23,35], it is important to determine the optimal phage concentration that will allow efficient phage attachment and amplification for the quantity of MDRAB present. Experiments on environmental ICU samples have identified A. baumannii on 39\% of the sampled surfaces with a mean $A$. baumannii DNA concentration of 19,696 copies [39]. Based on the results of our surface evaluation, we recommend that a phage concentration of at least $10^{7} \mathrm{PFU} / \mathrm{cm}^{2}$ be applied to surfaces in ICUs. This approach may not be suitable for the treatment of large surfaces, but may be useful for small biomedical devices. Abuladze et al. suggested a glass matrix is easier to decontaminate than gypsum [26]. Thus, the phage decontamination efficiency for different surfaces such as gypsum, plastic, Teflon, or other polymers may vary, and requires further investigation. In addition to phage concentration, the incubation time is also critical for surface applications. When a high phage concentration $\left(10^{8} \mathrm{PFU} /\right.$ slide) was used to treat a surface contaminated with bacteria at a concentration of $10^{5} \mathrm{CFU} / \mathrm{slide}$, an incubation time of 5 min resulted in a $96 \%$ reduction of A. baumannii M3237 numbers. This incubation time was caused a $94 \%$ reduction in the number of Escherichia coli $\mathrm{O} 157: \mathrm{H7}$ [26] under the same test conditions.

MDRAB can be transmitted via the hands of healthcare personnel. However, frequent or improper hand washing can cause skin to lose moisture or become irritated, reducing the hand washing rate despite intensive hand washing educational programs. Therefore, the addition of paraffin oil and glycerol to the formulation of antiseptic hand wash might retain skin moisture and reduce the transmission of MDRAB from the hands of health-care workers to patients. Alcohol-based hand rubs could reduce skin irritation [41] and reduce the number of bacteria more effectively than soap and water in a number of experimental models [42,43]. However, A. baumannii may metabolize low levels of alcohol to become more virulent [20]. Thus, an alternative hand washing approach is required to prevent microorganisms becoming tolerant to alcohol-based disinfectants in the future.

In this study, we designed two antiseptic hand wash experiments and observed a difference in the bactericidal effect between phage-containing lotion and glycerol solution, possibly related to the stability of $\phi A B 2$ in different media. Because the detailed compositions of commercial creams are proprietary, it is difficult to explain the unpredictable changes of phage numbers in the cream, as phages could aggregate, disaggregate, or decay after long storage periods. O'Flaherty et al. demonstrated that $S$. aureus-specific phage $\mathrm{K}$ exhibited antibacterial activity when incorporated into a bismuth-based cream [34]. The bismuth cream exhibited well antibacterial activity, but the related phage stability was not reported. In contrast, we observed that $\phi \mathrm{AB} 2$ was stable in $10 \%$ glycerol after 90 days storage at room temperature. Glycerol is a common cryoprotectant for phage infectivity during storage at temperatures between -20 and $-70^{\circ} \mathrm{C}$. Other phages, including F-specific RNA bacteriophages, and Bacteroides fragilis-specific phages, are also stable in $10 \%$ glycerol for up to 50 days [44] and can retain their infectivity with even longer storage times.

\section{Conclusions}

Since the introduction of antibiotics for clinical use, antibiotic-resistant bacteria, such as MDRAB, have emerged as important nosocomial pathogens worldwide. Our study used $\phi A B 2$ as a model phage to demonstrate its potential for the prevention of nosocomial MDRAB infections. As MDRAB are resistant to almost all currently available antibiotics and sanitizers, phages represent an alternative environmental decontamination approach. Although some studies have focused on isolating and characterizing new phages with a broader host range, further information regarding the stability of phages in different environments is required before these phages are used in hospitals. While phages could be used to decontaminate environmental surfaces naturally contaminated by MDRAB, when bacterial cell numbers are low and the surface area is large, a high phage concentration $\left(>10^{7} \mathrm{PFU} / \mathrm{cm}^{2}\right)$ is required to ensure contact between phages and their hosts. This study demonstrated that high concentrations of phages might be inoculated into a lotion or glycerol and used as an antiseptic hand wash. However, the phage concentration and incubation time should be carefully determined to identify the optimal bactericidal effect on MDRAB.

\section{Methods}

\section{Bacterial host strain and culture}

We used A. baumannii M3237 as a bacterial host, instead of an antibiotic-sensitive strain such as A. baumannii ATCC 17978, for practical simulation of the bactericidal effect of $\phi A B 2$ on MDRAB in a hospital environment. $A$. baumannii M3237was purchased from the Bioresource Collection and Research Center of Taiwan (BCRC 80276). A. baumannii M3237 is a MDRAB clinical isolate from the Buddhist Tzu-Chi General Hospital and was maintained and grown in LB or agar at $37^{\circ} \mathrm{C}$.

\section{Phage preparation}

$\phi A B 2$ was isolated from the raw sewage of a local hospital [35]. A high-titer stock of phage $\phi A B 2\left(10^{9}-10^{10}\right.$ 
plaque-forming units (PFU)/ml) was prepared via plate lysis and elution. $\$ \mathrm{AB} 2$ was propagated and assayed in triplicate using the double-agar-layer method as previously described [45].

\section{Phage adsorption assay}

A. baumannii M3237 was infected with phage $\phi A B 2$ at a multiplicity of infection (MOI; phage concentration/ bacterial concentration) of 0.001 and incubated at room temperature. The bacterial host $A$. baumannii ATCC 17978 was also evaluated for comparison. Samples $(100 \mu \mathrm{l})$ were taken at 2-min intervals for $10 \mathrm{~min}$, diluted in $0.9 \mathrm{ml}$ of cold LB, centrifuged $(12,000 \times g, 5 \mathrm{~min})$, and supernatants containing unadsorbed phages were titrated.

\section{Effect of temperature on $\phi A B 2$ stability}

фAB2 stock $\left(10^{10} \mathrm{PFU} / \mathrm{ml}\right)$ was diluted to $10^{8} \mathrm{PFU} / \mathrm{ml}$ with distilled water. The mixed phage solution was subsequently divided into $1 \mathrm{ml}$ vials and stored at $-20^{\circ} \mathrm{C}, 4^{\circ} \mathrm{C}$, or $25^{\circ} \mathrm{C}$. At various time points up to 360 days, solution from one vial at each temperature was inoculated for plaque assay. Used vials were discarded. To assess the effect of refreezing on phage survival, a vial with $500 \mathrm{ml}$ of a $10^{8} \mathrm{PFU} / \mathrm{ml}$ phage solution was stored at $-20^{\circ} \mathrm{C}$ and inoculated for plaque assays at various time points, after which the solution was stored at $-20^{\circ} \mathrm{C}$ again until the next sampling time.

\section{Effect of $\mathrm{pH}$ on $\phi A B 2$ stability}

The stability of $\phi A B 2$ at different $\mathrm{pH}$ values was determined by mixing $10^{10} \mathrm{PFU} / \mathrm{ml}$ of $\phi A B 2$ suspension with sterile water at different $\mathrm{pH}$ values $(\mathrm{pH} 2,4,7$, or 11$)$ to obtain a $100 \mathrm{ml}$ phage solution with a final phage concentration of $10^{8} \mathrm{PFU} / \mathrm{ml}$. The $\mathrm{pH}$ was adjusted with $1 \mathrm{~N}$ $\mathrm{HCl}$ or $\mathrm{KOH}$. After phage solutions were prepared, the initial concentration was determined within $5 \mathrm{~min}$, and then stored at $25^{\circ} \mathrm{C}$ until used.

\section{Effect of chloroform concentration on $\phi A B 2$ stability}

Briefly, phage solutions $\left(10^{8} \mathrm{PFU} / \mathrm{ml}\right)$ were exposed to $0.5 \%$ or $2 \%$ chloroform. The first sample was inoculated within $5 \mathrm{~min}$ to determine the initial concentration, and the solution was then inoculated for plaque assays at different storage times up to 360 days.

\section{Stability of $\phi A B 2$ on glass slides}

Aliquots of $100 \mu \mathrm{l}$ of a $10^{9} \mathrm{PFU} / \mathrm{ml}$ QAB2 suspension were spiked on the surface of sterilized glass slides $\left(10^{8}\right.$ PFU/13.8 $\mathrm{cm}^{2}$ surface), and incubated in a biosafety hood at room temperature for $30 \mathrm{~min}$ until completely dry. At various time points, a spiked glass slide was placed into a conical tube with $20 \mathrm{ml}$ of peptone and gently vortexed for $30 \mathrm{~s}$. $\phi A B 2$ recovered in the eluant was enumerated by plaque assay. All desiccation experiments were performed at room temperature $\left(25^{\circ} \mathrm{C}\right)$ and $55-65 \%$ relative humidity.

\section{Bactericidal effect of $\phi A B 2$ in a liquid suspension}

To determine the bactericidal effect of $\$ A B 2$ in suspension, A. baumannii M3237 was cultured overnight and then transferred to a flask and incubated at $37^{\circ} \mathrm{C}$ until reaching an $\mathrm{OD}_{600}$ of $1.0\left(5 \times 10^{8} \mathrm{CFU} / \mathrm{ml}\right)$. A. baumannii M3237 cultures were then serially diluted to obtain final concentrations of $5 \times 10^{6}, 5 \times 10^{5}$ or $5 \times 10^{4} \mathrm{CFU} / \mathrm{ml}$. A $1 \mathrm{ml}$ aliquot of each concentration was mixed with $1 \mathrm{ml}$ of $\phi A B 2$ suspension to obtain a final phage concentration of $10^{3}, 10^{5}$, or $10^{8} \mathrm{PFU} / \mathrm{ml}$. Phage-free culture (containing bacteria only) was included as a control. Following a 5- or 10-min incubation, host and phage mixtures were immediately passed through $47-\mathrm{mm}$ diameter membrane filters (pore size of $0.45 \mu \mathrm{m}$, Pall Corporation) and washed with $20 \mathrm{ml}$ of phosphate-buffered saline (PBS) to remove unattached phages [26]. Washed filters were placed in separate dishes containing LB agar, and following 24-h incubation at $37^{\circ} \mathrm{C}$, the number of recovered $A$. baumannii M3237 was calculated by counting colonies on each filter. The survival rate was calculated as $\log _{10}$ of $\mathrm{N}_{\mathrm{t}} / \mathrm{N}_{0}$, where $\mathrm{N}_{0}$ is the number of $A$. baumannii M3237 colonies recovered on the control filter and $\mathrm{N}_{\mathrm{t}}$ is the number of colonies on the test filter.

\section{Bactericidal effect of $\phi A B 2$ on a glass slide}

To determine the bactericidal effect of $\phi A B 2$ on a glass surface, glass slides were sterilized, pre-contaminated with $A$. baumannii M3237 by spreading diluted culture stock solution on the glass surface to obtain concentrations of $10^{4}, 10^{5}$, and $10^{6} \mathrm{CFU} /$ slide and dried for $30 \mathrm{~min}$ in a biosafety hood at room temperature. Then, slides were divided into two groups. 1) test: treated with фAB2 to reach a concentration of $10^{3}, 10^{5}$, or $10^{8} \mathrm{PFU} /$ slide and 2) control: treated with phage-free suspension. After the $\phi A B 2$ solution or phage-free suspension was applied to the $A$. baumannii M3237 slide, they were stored for 5 or $10 \mathrm{~min}$ at room temperature. Residual $A$. baumannii M3237 particles on the test or control slides were eluted with $20 \mathrm{ml}$ of peptone into a conical tube, gently vortexed for $30 \mathrm{~s}$, serially diluted and passed through membrane filters, as above. The filters were then washed with PBS, placed on LB agar plates, and incubated for $24 \mathrm{~h}$ at $37^{\circ} \mathrm{C}$. The number of $A$. baumannii M3237 colonies that grew on each filter was counted and the survival rate was calculated.

\section{Production of $\phi A B 2$ hand sanitizer in a paraffin oil-based lotion}

A commercial cream containing paraffin mineral oil (First Chemical Works, Taipei, Taiwan) was combined with $\phi A B 2$ in a conical tube and sterile water added to 
obtain a paraffin oil-based lotion with a final concentration of $10 \%(\mathrm{v} / \mathrm{v})$ paraffin oil and a phage concentration of $10^{8} \mathrm{PFU} / \mathrm{ml}$. The phage-containing lotion was stored at room temperature up to 30 days. At each sampling point, the phage lotion was inoculated for plaque assays to obtain a kinetic curve of the phage concentration.

The relationship between the number of residual $\phi A B 2$ phages in the lotion and their ability to inhibit MDRAB was evaluated. At each sampling point, LB agar was pre-contaminated with $A$. baumannii M3237 suspension to obtain surface concentrations of $5 \times 10^{1}, 5 \times$ $10^{2}$, and $5 \times 10^{3} \mathrm{CFU} / \mathrm{ml}$. Contaminated agar plates were dried for $30 \mathrm{~min}$ in a biosafety hood at room temperature and divided into two groups: test agars received 0.1 or $0.5 \mathrm{ml}$ of the phage-containing lotion to simulate the volumes of lotion used by most hand cream consumers and control. The control agars consisted of a phage-free lotion. The test and control agars were then incubated for $24 \mathrm{~h}$ at $37^{\circ} \mathrm{C}$, and bacterial recovery counts calculated by comparing the number of $A$. baumannii M3237 colonies from the test agars with those from the control agars.

\section{$\phi A B 2$ in glycerol as a hand sanitizer}

Briefly, the phage stock was mixed with glycerol to obtain a solution of $10 \%(\mathrm{v} / \mathrm{v})$ glycerol $/ 10^{8} \mathrm{PFU} / \mathrm{ml}$ phage and stored at room temperature for up to 180 days to obtain a kinetic curve of the phage variation during this period. Phage stability and ability to inhibit $A$. baumannii M3237 was determined as described above for lotions.

\section{Statistical analysis}

Statistical analyses were performed using SPSS, version 17.0 (SPSS Institute Inc., Chicago, IL, USA). Measurement of $\phi A B 2$ bactericidal effect in liquid suspensions and glass slides, comparison of A. baumannii M3237 survival rates with different incubation times and control sets and reduction of viable $A$. baumannii M3237 by $\phi A B 2$ lotion or glycerol was performed using one-way ANOVA, followed by Tukey's test.

\section{Competing interests}

The authors declare that they have no competing interests.

\section{Authors' contributions}

LKC and YLL performed the experiments and analyses. AH and KCC provided test materials and participated in the analysis of bacteria. NTL and MJL participated in the bacteriophage experiments. CCT conceived of the study and drafted the manuscript. All authors read and approved the final manuscript.

\section{Acknowledgments}

We thank Prof. Yi-Hsiung Tseng for critical reading of our manuscript. This work was supported by grant NSC 100-2314-B-320-003 from the National Science Council, Republic of China; grant TCSP99-03-05 from Buddhist Tzu Chi General Hospital; and grant TCIRP98003-03 from Tzu Chi University.
Yu-Lin Liu was supported by a graduate scholarship from the latter grant during part of this research project.

\section{Author details}

'Institute of Medical Sciences, Department of Laboratory Diagnostics, College of Medicine, Tzu Chi University, Hualien, Taiwan. ${ }^{2}$ Department of Laboratory Medicine, Clinical Pathology, Emerging Infectious Pathogen Research Laboratory, Buddhist Tzu Chi General Hospital, Hualien, Taiwan. ${ }^{3}$ Department and Graduate Institute of Public Health, Tzu Chi University, Hualien, Taiwan. ${ }^{4}$ Department of Laboratory Medicine and Biotechnology, Tzu Chi University, Hualien, Taiwan. ${ }^{5}$ Master Program, Microbiology, Immunology, and Biochemistry, School of Medicine, Tzu Chi University, Hualien, Taiwan.

Received: 10 April 2013 Accepted: 2 July 2013

Published: 8 July 2013

\section{References}

1. Bergogne-Berezin E, Towner KJ: Acinetobacter spp. as nosocomial pathogens: microbiological, clinical, and epidemiological features. Clin Microbiol Rev 1996, 9:148-165.

2. Villegas MV, Hartstein Al: Acinetobacter outbreaks, 1977-2000. Infect Control Hosp Epidemiol 2003, 24:284-295.

3. Okpara AU, Maswoswe Jj: Emergence of multidrug-resistant isolates of Acinetobacter baumannii. Am J Hosp Pharm 1994, 51:2671-2675.

4. Gaynes R, Edwards JR: Overview of nosocomial infections caused by gram-negative bacilli. Clin Infect Dis 2005, 41:848-854.

5. Meric M, Kasap M, Gacar G, Budak F, Dundar D, Kolayli F, Eroglu C, Vahaboglu H: Emergence and spread of carbapenem-resistant Acinetobacter baumannii in a tertiary care hospital in Turkey. FEMS Microbiol Lett 2008, 282:214-218.

6. Hsueh PR, Teng LJ, Chen CY, Chen WH, Yu CJ, Ho SW, Luh KT: Pandrugresistant Acinetobacter baumannii causing nosocomial infections in a university hospital, Taiwan. Emerg Infect Dis 2002, 8:827-832.

7. Annual Report of Nosocomial Infections Surveillance System: Annual Report of Nosocomial Infections Surveillance System. Taiwan: Center for Disease Control; 2009. http://www.cdc.gov.tw/english/.

8. Dijkshoorn L, Nemec A, Seifert H: An increasing threat in hospitals: multidrugresistant Acinetobacter baumannii. Nat Rev Microbiol 2007, 5:939-951.

9. Chang HL, Tang CH, Hsu YM, Wan L, Chang YF, Lin CT, Tseng YR, Lin YJ, Sheu JJ, Lin CW, et al: Nosocomial outbreak of infection with multidrugresistant Acinetobacter baumannii in a medical center in Taiwan. Infect Control Hosp Epidemiol 2009, 30:34-38.

10. Sengstock DM, Thyagarajan R, Apalara J, Mira A, Chopra T, Kaye KS: Multidrug-resistant Acinetobacter baumannii: an emerging pathogen among older adults in community hospitals and nursing homes. Clin Infect Dis 2010, 50:1611-1616.

11. Joseph NM, Sistla S, Dutta TK, Badhe AS, Rasitha D, Parija SC: Role of intensive care unit environment and health-care workers in transmission of ventilator-associated pneumonia. J Infect Dev Ctries 2010, 4:282-291.

12. Wang CY, Wu HD, Lee LN, Chang HT, Hsu YL, Yu CJ, Yang PC, Hsueh PR: Pasteurization is effective against multidrug-resistant bacteria. Am J Infect Control 2006, 34:320-322.

13. Rastogi VK, Wallace L, Smith LS: Disinfection of Acinetobacter baumanniicontaminated surfaces relevant to medical treatment facilities with ultraviolet C light. Mil Med 2007, 172:1166-1169.

14. Doidge M, Allworth AM, Woods M, Marshall P, Terry M, O'Brien K, Goh HM, George N, Nimmo GR, Schembri MA, et al: Control of an outbreak of carbapenem-resistant Acinetobacter baumannii in Australia after introduction of environmental cleaning with a commercial oxidizing disinfectant. Infect Control Hosp Epidemiol 2010, 31:418-420.

15. Donahue M, Watson LR, Torress-Cook A, Watson PA: Novel use of antimicrobial hand sanitizer in treatment of nosocomial Acinetobacter infection. Orthopedics 2009, 32:58.

16. Martro E, Hernandez A, Ariza J, Dominguez MA, Matas L, Argerich MJ, Martin R, Ausina V: Assessment of Acinetobacter baumannii susceptibility to antiseptics and disinfectants. J Hosp Infect 2003, 55:39-46.

17. Sharma M, Hudson JB: Ozone gas is an effective and practical antibacterial agent. Am J Infect Control 2008, 36:559-563.

18. Wong MS, Sun DS, Chang HH: Bactericidal performance of visible-light responsive titania photocatalyst with silver nanostructures. PLoS One 2010, 5:e10394. 
19. Wisplinghoff $H$, Schmitt $R$, Wohrmann A, Stefanik D, Seifert $H$ : Resistance to disinfectants in epidemiologically defined clinical isolates of Acinetobacter baumannii. J Hosp Infect 2007, 66:174-181.

20. Edwards J, Patel G, Wareham DW: Low concentrations of commercial alcohol hand rubs facilitate growth of and secretion of extracellular proteins by multidrug-resistant strains of Acinetobacter baumannii. J Med Microbiol 2007, 56:1595-1599.

21. Hudson JA, Billington C, Carey-Smith G, Greening G: Bacteriophages as biocontrol agents in food. J Food Prot 2005, 68:426-437.

22. Bigwood T, Hudson JA, Billington C: Influence of host and bacteriophage concentrations on the inactivation of food-borne pathogenic bacteria by two phages. FEMS Microbiol Lett 2009, 291:59-64.

23. Guenther S, Huwyler D, Richard S, Loessner MJ: Virulent bacteriophage for efficient biocontrol of Listeria monocytogenes in ready-to-eat foods. Appl Environ Microbiol 2009, 75:93-100.

24. Garcia P, Martinez B, Rodriguez L, Rodriguez A: Synergy between the phage endolysin $\mathrm{LysH} 5$ and nisin to kill Staphylococcus aureus in pasteurized milk. Int J Food Microbiol 2010, 141:151-155.

25. Kim KP, Klumpp J, Loessner MJ: Enterobacter sakazakii bacteriophages can prevent bacterial growth in reconstituted infant formula. Int J Food Microbiol 2007, 115:195-203.

26. Abuladze T, Li M, Menetrez MY, Dean T, Senecal A, Sulakvelidze A: Bacteriophages reduce experimental contamination of hard surfaces, tomato, spinach, broccoli, and ground beef by Escherichia coli 0157:H7. Appl Environ Microbiol 2008, 74:6230-6238

27. Kocharunchitt C, Ross T, McNeil DL: Use of bacteriophages as biocontrol agents to control Salmonella associated with seed sprouts. Int J Food Microbiol 2009, 128:453-459.

28. Obeso JM, Garcia P, Martinez B, Arroyo-Lopez FN, Garrido-Fernandez A Rodriguez A: Use of logistic regression for prediction of the fate of Staphylococcus aureus in pasteurized milk in the presence of two lytic phages. Appl Environ Microbiol 2010, 76:6038-6046.

29. Garcia P, Madera C, Martinez B, Rodriguez A, Evaristo Suarez J: Prevalence of bacteriophages infecting Staphylococcus aureus in dairy samples and their potential as biocontrol agents. J Dairy Sci 2009, 92:3019-3026.

30. FDA: Food additives permitted for direct addition to food for human consumption; bacteriophage preparation. Fed Regist 2006, 71:47729-47732

31. Barbolla RE, Centron D, Maimone S, Rospide F, Salgueira C, Altclas J, Catalano M: Molecular epidemiology of Acinetobacter baumannii spread in an adult intensive care unit under an endemic setting. Am J Infect Control 2008, 36:444-452

32. Otter JA, Yezli S, French GL: The role played by contaminated surfaces in the transmission of nosocomial pathogens. Infect Control Hosp Epidemiol 2011, 32:687-699.

33. Monk AB, Rees CD, Barrow P, Hagens S, Harper DR: Bacteriophage applications: where are we now? Lett Appl Microbiol 2010, 51:363-369.

34. O'Flaherty S, Ross RP, Meaney W, Fitzgerald GF, Elbreki MF, Coffey A: Potential of the polyvalent anti-Staphylococcus bacteriophage $K$ for control of antibiotic-resistant staphylococci from hospitals. Appl Environ Microbiol 2005, 71:1836-1842

35. Lin NT, Chiou PY, Chang KC, Chen LK, Lai MJ: Isolation and characterization of phi AB2: a novel bacteriophage of Acinetobacter baumannii. Res Microbiol 2010, 161:308-314.

36. Hagens S, Loessner MJ: Application of bacteriophages for detection and control of foodborne pathogens. Appl Microbiol Biotechnol 2007, 76:513-519.

37. Iriarte FB, Balogh B, Momol MT, Smith LM, Wilson M, Jones JB: Factors affecting survival of bacteriophage on tomato leaf surfaces. Appl Environ Microbiol 2007, 73:1704-1711.

38. Chang KC, Lin NT, Hu A, Lin YS, Chen LK, Lai MJ: Genomic analysis of bacteriophage $\varphi A B 1$, a $\varphi K M V$-like virus infecting multidrug-resistant Acinetobacter baumannii. Genomics 2011, 97:249-255.

39. McConnell MJ, Perez-Ordonez A, Perez-Romero P, Valencia R, Lepe JA Vazquez-Barba I, Pachon J: Quantitative real-time PCR for detection of Acinetobacter baumannii colonization in the hospital environment. J Clin Microbiol 2012, 50:1412-1414.

40. Yang $H$, Liang $L$, Lin S, Jia S: Isolation and characterization of a virulent bacteriophage $A B 1$ of Acinetobacter baumannii. BMC Microbiol 2010, 10:131.
41. Boyce JM, Kelliher S, Vallande N: Skin irritation and dryness associated with two hand-hygiene regimens: soap-and-water hand washing versus hand antisepsis with an alcoholic hand gel. Infect Control Hosp Epidemiol 2000, 21:442-448.

42. Goroncy-Bermes P, Schouten MA, Voss A: In vitro activity of a nonmedicated handwash product, chlorhexidine, and an alcohol-based hand disinfectant against multiply resistant gram-positive microorganisms. Infect Control Hosp Epidemiol 2001, 22:194-196.

43. Trick WE, Vernon MO, Hayes RA, Nathan C, Rice TW, Peterson BJ, Segreti J, Welbel SF, Solomon SL, Weinstein RA: Impact of ring wearing on hand contamination and comparison of hand hygiene agents in a hospital. Clin Infect Dis 2003, 36:1383-1390.

44. Mendez J, Jofre J, Lucena F, Contreras N, Mooijman K, Araujo R: Conservation of phage reference materials and water samples containing bacteriophages of enteric bacteria. J Virol Methods 2002, 106:215-224.

45. Adams M: Bacteriophages. In Edited by Hershey AD. New York: Interscience; 1959:137-159.

doi:10.1186/1471-2180-13-154

Cite this article as: Chen et al:: Potential of bacteriophage $\triangle A B 2$ as an environmental biocontrol agent for the control of multidrug-resistant Acinetobacter baumannii. BMC Microbiology 2013 13:154.

\section{Submit your next manuscript to BioMed Central and take full advantage of:}

- Convenient online submission

- Thorough peer review

- No space constraints or color figure charges

- Immediate publication on acceptance

- Inclusion in PubMed, CAS, Scopus and Google Scholar

- Research which is freely available for redistribution 